\title{
Equipamento de Proteção Individual na educação profissional: sensibilizar para prevenir acidentes e promover saúde ${ }^{1}$
}

\author{
Reidevandro Machado da Silva Pimentel \\ Enfermeiro Pelas Faculdades Integradas do Tapajós/ Unama. \\ Especialista em Enfermagem do Trabalho pelas Faculdades Integradas do Tapajós/ Unama. \\ Especialista em Educação Permanente na Gestão do SUS Amazonas pela Fundação Oswaldo Cruz \\ Especialista em Enfermagem Intensiva de Alta Complexidade pela Faculdade Literatus/ Estácio do Amazonas \\ Mestre em Educação pela Universidade Federal Rural do Rio de Janeiro \\ Enfermeiro do Instituto Federal de Educação, Ciência e Tecnologia do Amazonas- IFAM \\ $\triangle$ reidevandromachado@yahoo.com \\ Sandra Maria Gomes Thomé \\ Médica Veterinária pela Universidade Federal Fluminense \\ Mestra em Meio Ambiente pela Universidade Federal do Rio de Janeiro \\ Doutora em Epidemiologia Experimental Aplicada às Zoonoses pela Universidade de São Paulo \\ Docente Associada da Universidade Federal Rural do Rio de Janeiro \\ $\triangle$ sandramgthome@yahoo.com.br
}

Recebido em 4 de setembro de 2020

Aceito em 19 de setembro de 2021

\section{Resumo:}

Acidentes de trabalho podem provocar consequências traumáticas, que vão desde a perda permanente ou temporária da capacidade laborativa até a morte. Assim, esta pesquisa teve como objetivo avaliar a percepção de servidores e discentes do terceiro ano do Ensino Médio Integrado em Agropecuária e terceiro módulo do Curso Subsequente de Recursos Pesqueiros, do Instituto Federal de Educação, Ciência e Tecnologia do Amazonas (IFAM), Campus Parintins, sobre a importância do uso de Equipamentos de Proteção Individual (EPI) na promoção da saúde e prevenção de acidentes ou doenças, durante as atividades práticas dos cursos. Tratou-se de uma pesquisa qualitativa, com aplicação de entrevistas, referenciada pela Análise de Conteúdo de Bardin (2011). Foram entrevistados 31 discentes e 14 servidores. Os resultados apontaram o não uso de EPI, inexistência de normas internas relativas à saúde e segurança de servidores e discentes, obrigatoriedade de fornecimento de EPI a servidores e inexistência de legislação clara quanto ao fornecimento de EPI para discentes. Também revelaram exposição a riscos e acidentes, com peixes agressivos, animais peçonhentos, produtos tóxicos e ferramentas com potencial lesivo. O estudo esclareceu a importância do uso de EPI e sugeriu a necessidade de capacitação sobre reconhecimento e prevenção de acidentes e doenças em situações emergenciais.

Palavras-chave: Educação profissional, promoção da saúde, prevenção de doenças.

\section{Individual Protection Equipment in professional education: raising awareness to prevent accidents and promote health}

\begin{abstract}
:
\footnotetext{
${ }^{1}$ Este artigo faz parte da Dissertação de Mestrado em Educação de Reidevandro Machado da Silva Pimentel.

Programa de Pós-Graduação em Educação Agrícola, Universidade Federal Rural do Rio de Janeiro.
}

Orientador: Sandra Maria Gomes Thomé, Ano: 2019.
\end{abstract}

The objective of this research was to evaluate the perception of servants and students of the third year of Integrated High School in Agriculture and Livestock and the third module of the Subsequent Course on Fishing Resources of the Instituto Federal de Educação, Ciência e Tecnologia do Amazonas (IFAM), Parintins Campus, on the use of Individual Protective Equipment (IPE) in the practical activities of these courses. It was a qualitative research, with application of interviews, referenced by Content Analysis. 31 students and 14 servants were 
interviewed. The results pointed out the non-use of IPE, inexistence of internal norms relative to the health and security of servers and students, obligatory supply of IPE to servers and inexistence of clear legislation regarding the supply of IPE to students. They also revealed exposure to risks and accidents, with aggressive fish, venomous animals, toxic products and tools with harmful potential. The study clarified the importance of the use of IPE and suggested the need for training on the recognition and prevention of accidents and diseases in emergency situations.

Keywords: Professional education, health promotion, diseases prevention.

\title{
Equipos de Protección Personal en la educación profesional: sensibilizar para prevenir accidentes y promover la salud
}

\begin{abstract}
Resumen:
El objetivo de esta investigación fue evaluar la percepción de servidores y estudiantes del tercer año de Escuela Secundaria Integrada en Agricultura y tercer módulo del Curso Subsecuente de Recursos Pesqueros, del Instituto Federal de Educação, Ciência e Tecnología do Amazonas (IFAM), Campus Parintins, sobre el uso de Equipos de Protección Personal (PPE) en las actividades prácticas de estos cursos. Fue una investigación cualitativa, con aplicación de entrevistas, referida por el Análisis de Contenido. Treinta y un estudiantes y 14 servidores fueron entrevistados. Los resultados indicaron la no utilización de los PPE, la falta de normas internas relativas a la salud y la seguridad de los servidores y estudiantes, la obligación de proporcionar PPE a los servidores y la falta de una legislación clara en relación con la provisión de PPE a los estudiantes. También revelaron la exposición a riesgos y accidentes, con peces agresivos, animales venenosos, productos tóxicos y herramientas con potencial nocivo. El estudio aclaró la importancia del uso del PPE y sugirió la necesidad de capacitación sobre reconocimiento y prevención de accidentes y enfermedades en situaciones de emergencia.
\end{abstract}

Palabras clave: Educación profesional, promoción de la salud, prevención de enfermedades.

\section{INTRODUÇÃO}

No Brasil, desde o início do século XX, diversos projetos buscaram instituir uma lei específica para regulamentar a infortunística, que é parte da Medicina Legal que estuda os acidentes do trabalho, as doenças profissionais e as doenças do trabalho. Esse esforço resultou na aprovação do Decreto Legislativo n. ${ }^{\circ}$ 3.724, de 15 de janeiro de 1919, considerado a primeira lei acidentária brasileira (BRASIL, 1919).

Barsano e Barbosa (2018) afirmaram que o acidente de trabalho, por ser um evento inesperado e indesejado, provoca no trabalhador consequências traumáticas, lesões corporais e reflexos danosos, que vão desde a perda permanente ou temporária de sua capacidade laborativa, até a morte. O reflexo dessas situações se estende principalmente à família, à empresa e à sociedade, uma vez que o acidente mais grave interrompe abruptamente sonhos e a trajetória profissional, podendo ainda impactar na produção, o que por sua vez, pode ocasionar queda na arrecadação de impostos, representando um impacto para a sociedade. 
Para que tais infortúnios fossem evitados, a Norma Regulamentadora n. 6, com última alteração dada pela Portaria n.ำ 877, de 24 de outubro de 2018, estabeleceu os Equipamentos de Proteção Individual (EPI), que são dispositivos ou produtos de uso pelo trabalhador, para proteção contra riscos suscetíveis de ameaçar sua segurança e saúde no trabalho (BRASIL, 2018).

No Instituto Federal de Educação, Ciência e Tecnologia do Amazonas (IFAM), Campus Parintins, mais precisamente nos cursos de Agropecuária e Recursos Pesqueiros, as atividades práticas são precedidas por certo planejamento; no entanto, o uso desses equipamentos ainda é negligenciado pelos servidores e discentes. Os principais aspectos que justificam essa situação estão relacionados ao não fornecimento de EPI para servidores e discentes pelo Instituto e à baixa renda dos discentes, impedindo sua aquisição.

Alguns riscos inerentes às práticas realizadas pelo curso de Recursos Pesqueiros em laboratório são o uso de objetos perfurocortantes, como tesouras, agulhas de sutura, pinças, estiletes, agulhas para tecer redes de pesca, e a manipulação de produtos químicos voláteis, sem o uso de exaustor e máscaras, contaminando desta forma o ambiente e provocando a inalação desses produtos. O manuseio proveniente do processo de utilização de carcaças e vísceras na fabricação de ração e a utilização de máquina trituradora industrial, também são exemplos de situações de risco.

No curso de Agropecuária, os riscos também estão presentes, visto que suas atividades práticas são realizadas integralmente em áreas rurais, com a utilização de instrumentos típicos da atividade agrícola, tais como, facão, enxadas, foices, machados, motosserras, máquinas roçadeiras, além da possibilidade de exposição a acidentes por animais peçonhentos. Tal contexto motivou esta pesquisa, no sentido de envidar esforços para compreender a razão das atividades práticas estarem sendo realizadas sem os cuidados de saúde e segurança necessários.

Assim, esta pesquisa teve como objetivo avaliar a percepção de docentes, técnicos agrícolas e discentes do terceiro ano do Ensino Médio Integrado em Agropecuária e terceiro módulo do Curso Subsequente de Recursos Pesqueiros, ambos pertencentes ao Instituto Federal de Educação, Ciência e Tecnologia do Amazonas (IFAM), Campus Parintins, sobre a importância do uso de Equipamentos de Proteção Individual na promoção da saúde e prevenção de acidentes ou doenças, durante as atividades práticas dos cursos. Ainda buscou, 
através da investigação perpetrada, verificar as atividades existentes no Campus acerca da promoção da saúde e prevenção de acidentes; identificar a percepção de servidores e estudantes sobre os riscos associados às atividades práticas; e, demonstrar caminhos para a promoção da saúde e prevenção de doenças e acidentes no Instituto.

\section{MATERIAL E MÉTODOS}

A pesquisa foi desenvolvida no Programa de Pós-Graduação em Educação Agrícola (PPGEA), Instituto de Agronomia, Universidade Federal Rural do Rio de Janeiro (UFRRJ), localizado no município de Seropédica, estado do Rio de Janeiro, no período de 2017 a 2019.

Caracterizou-se como pesquisa qualitativa, em razão da possibilidade de melhor análise e interpretação das impressões registradas pelos participantes, partindo de suas percepções com referência ao objeto de estudo. Segundo Minayo (2010), a pesquisa qualitativa trata de assuntos que não podem ser quantificados, envolvendo questões muito particulares das relações dos processos e dos fenômenos. Trabalha com “[...] o universo da produção humana que pode ser resumido nos mundos das relações, das representações e da intencionalidade do sujeito [...] que dificilmente pode ser traduzido em números e indicadores quantitativos" (MINAYO, 2010, p. 21).

A pesquisa elegeu como locus de estudo, o Instituto Federal de Educação, Ciência e Tecnologia do Amazonas (IFAM), Campus Parintins, município de Parintins, estado do Amazonas. O Campus possui área total de $61.825,40 \mathrm{~m}^{2}$ e coordenadas geográficas de 02³9'06”

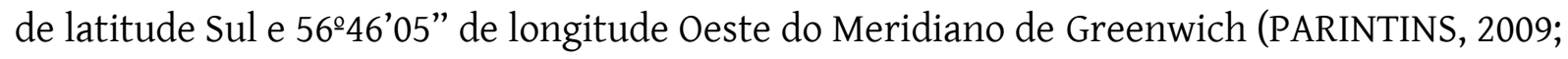
GOOGLE EARTH, 2019).

A população participante foi selecionada entre discentes do terceiro ano do Ensino Médio Integrado em Agropecuária e terceiro módulo do Curso Subsequente de Recursos Pesqueiros, além de servidores que atuavam diretamente nas turmas citadas. Quanto aos discentes, levou-se em consideração aqueles que já haviam passado por diversas disciplinas práticas e que, portanto, teriam acumulado experiências nas práticas realizadas em laboratório e campo. Quanto aos servidores, considerou-se as experiências vivenciadas em 
relação aos cursos citados e o tempo de serviço no IFAM, Campus Parintins. Assim, foram divididos em dois grupos:

O primeiro grupo foi composto por 31 discentes, sendo 18 do terceiro ano do Ensino Médio Integrado em Agropecuária e 13 do terceiro módulo do Curso Subsequente de Recursos Pesqueiros, com faixa etária entre 15 e 35 anos, de ambos os sexos, todos concludentes em 2019. Os entrevistados receberam um número em ordem crescente, sendo identificados com os códigos: DIS1 até DIS31.

O segundo grupo foi composto por 14 servidores, sendo 11 docentes e três técnicos, com faixa etária entre 25 e 45 anos, de ambos os sexos, todos servidores do IFAM, Campus Parintins. Os entrevistados receberam um número em ordem crescente, sendo identificados com os códigos: DOC1 até DOC11, para os docentes, e TEC1 até TEC3, para os técnicos.

Para coleta de dados, realizou-se entrevistas com os participantes da pesquisa, durante os meses de junho e julho de 2019. Para tanto, elaborou-se um roteiro a fim de nortear os entrevistados e ampliar as possibilidades de respostas referentes quanto a possíveis situações de risco e/ou acidentes vivenciados, sendo as respostas gravadas por meio de equipamento eletrônico (celular), e posteriormente transcritas, fielmente, para categorização e análise.

O roteiro para as entrevistas com os discentes constou dos seguintes indicadores: 1 ) histórico de acidente sofrido durante as atividades práticas; 2) testemunho de acidentes com colegas em atividades práticas; 3 ) existência de disciplinas voltadas para as normas de saúde e segurança do trabalho no currículo dos cursos investigados; 4) minimização dos acidentes ocorridos com o uso de EPI; e, 5) compreensão da responsabilidade de fornecimento do EPI.

O roteiro para as entrevistas com os servidores constou dos seguintes indicadores: 1 ) histórico de acidente sofrido durante as atividades práticas; 2) testemunho de acidentes com colegas em atividades práticas; 3 ) conhecimento de normas e procedimentos internos de segurança; 4) riscos e perigos nos locais das atividades práticas; e, 5) questões ligadas à promoção da saúde e prevenção de doenças e acidentes.

A entrevista revelou-se apropriada para a pesquisa visto que, de acordo com Gerhardt e Silveira (2009, p. 72), 
O pesquisador organiza um conjunto de questões (roteiro) sobre o tema que está sendo estudado, mas permite, e às vezes até incentiva, que o entrevistado fale livremente sobre assuntos que vão surgindo como desdobramentos do tema principal.

Os dados obtidos, a partir das entrevistas, foram categorizados e submetidos à proposta de Análise de Conteúdo, que segundo Bardin (2011), consiste no estabelecimento de unidades textuais manejáveis, permitindo alcançar uma representação simbólica, a subjetividade sobre o tema proposto.

Em todos os procedimentos utilizados foram obedecidos os critérios da ética na pesquisa com seres humanos, conforme a Resolução n.ำ 466/2012 do Conselho Nacional de Saúde (BRASIL, 2013), assim como, a apresentação e orientação aos servidores, responsáveis legais de menores e demais discentes, quanto ao preenchimento do Termo de Assentimento e do Termo de Consentimento Livre e Esclarecido.

Foi solicitado à Direção Geral do Campus Parintins anuência para realizar o estudo em tela, sendo autorizada em 29 de maio de 2019, por exigência do Comitê de Ética em Pesquisa. Em seguida, cadastrou-se o estudo na Plataforma Brasil, vinculando-o ao Comitê de Ética em Pesquisa do IFAM. Após análise do comitê, foi expedido o Certificado de Apresentação para Apreciação Ética (CAAE) n. ${ }^{\circ} 98129318.0 .0000 .8119$ e o Parecer n. 3.399.139, aprovando a realização da pesquisa.

\section{RESULTADOS}

Referente às entrevistas com os discentes, mais precisamente aquelas aplicadas sobre o indicador "histórico de acidente sofrido durante as atividades práticas", a Figura 1 exibe as respostas disponibilizadas pelos 31 discentes.

Figura 1. Situações vivenciadas pelos discentes quanto a acidentes sofridos. 


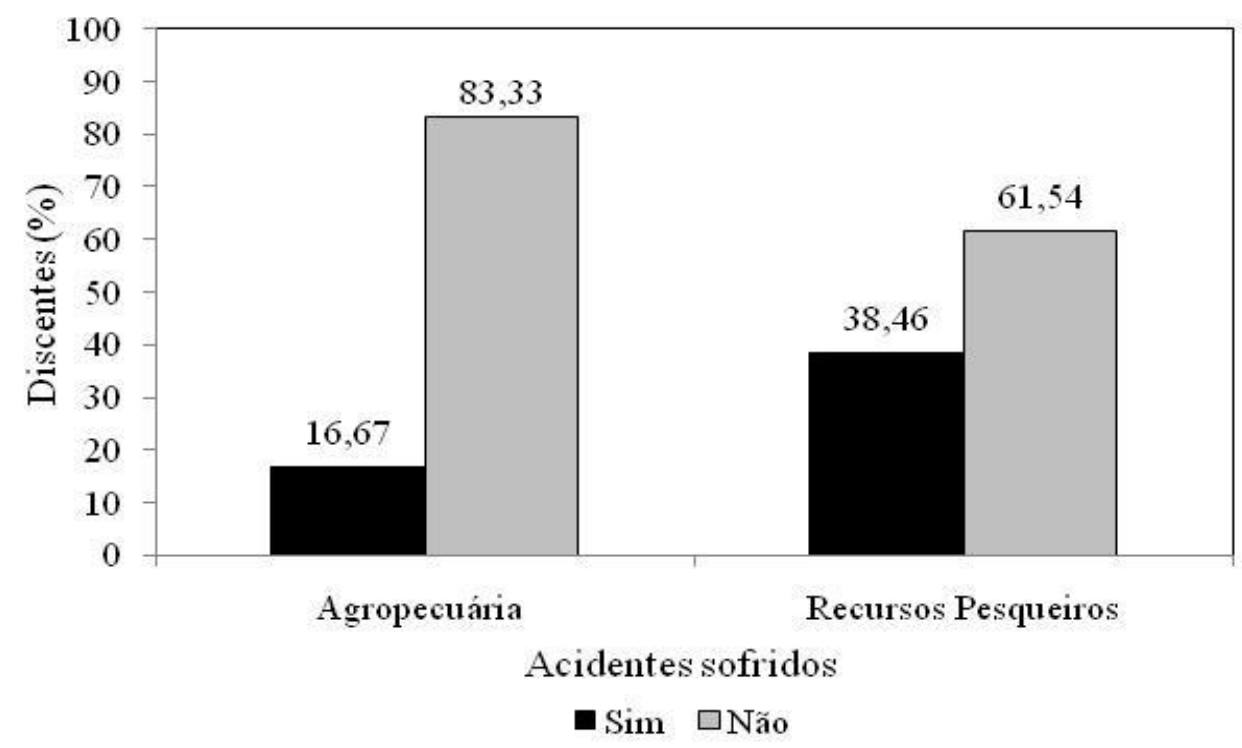

Fonte: Própria autoria.

Dentre os 18 discentes do terceiro ano do Ensino Médio Integrado em Agropecuária, três (16,67\%) relataram já ter sofrido acidentes, e 15 (83,33\%) responderam que não. Algumas falas descrevem o mencionado por aqueles que relataram algum tipo de acidente:

Discente 8 (DIS8): Só ocorreu riscos de se acidentar, de se bater com a enxada, porque eu não sabia capinar, aí quando eu fui tentar capinar, deu no meu pé. Só que não cortou não.

DIS11: Como não tinha essa parte do EPI eu me acidentei com uma tesoura de poda. Eu cortei meu dedo.

DIS24: Só mesmo corte, mas nada demais. Foi no dedo, a gente tava fazendo o bezerreiro e machucou.

Dentre os 13 discentes do terceiro módulo do Curso Subsequente de Recursos Pesqueiros, cinco $(38,46 \%)$ relataram já ter sofrido acidentes, e oito $(61,54 \%)$ responderam que não, conforme especificado em algumas falas:

DIS5: Já sim, quando a gente vai fazer atividades práticas geralmente acontece né acidentes porque às vezes tá sem o EPI completo e a gente deixa de não fazer as atividades.

DIS19: Sim, já cortei a mão com faca na manipulação do pescado. 
Com relação às respostas prestadas durante a entrevista sobre o indicador "testemunho de acidentes com colegas em atividades práticas", a Figura 2 exibe aquelas disponibilizadas pelos 31 discentes.

Figura 2 - Situações vivenciadas pelos discentes quanto a acidentes presenciados.

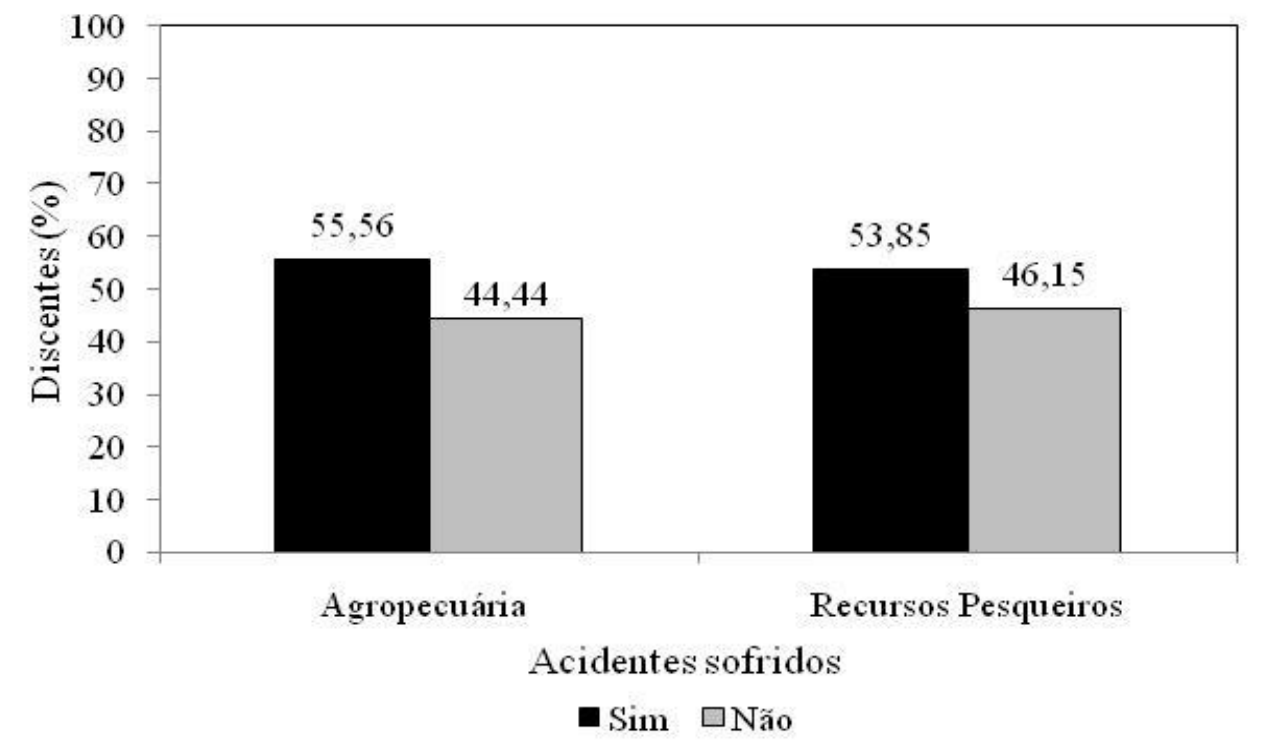

Fonte: Própria autoria.

Dentre os 18 discentes do terceiro ano do Ensino Médio Integrado em Agropecuária, 10 (55,56\%) afirmaram positivamente o testemunho de acidentes com colegas e oito (44,44\%), responderam negativamente. Algumas falas exemplificam as respostas:

DIS12: Teve uma vez que teve um colega da gente que se acidentou, mas não foi nada grave. Ele só fez cortar o dedo dele mesmo.

DIS18: Já vi alguns colegas; apenas cortes de terçado; entrar farpas de madeiras.

Dentre os 13 discentes do terceiro módulo do Curso Subsequente de Recursos Pesqueiros, sete $(53,85 \%)$ disseram já ter presenciado acidentes com colegas, e seis $(46,15 \%)$, negaram. As falas a seguir descrevem algumas afirmativas: 
DIS1: Sim, em questão que a gente foi lá no campo atrás do IFAM e a gente não deu com a casa de caba (vespas) e acabou ferrando ele. Ele ficou um pouco com algumas vermelhidões onde a caba o ferrou.

DIS23: A gente tava fazendo as metragens e tudo mais; colocando os piquetes e tem que tá cortando, né? Aí, minha colega foi cortar e não tinha luva, né? Tava sem e pegou no dedo e saiu muito sangue; fora o sol, né? Eles têm problemas na pele e tudo mais.

Analisando agora o indicador "existência de disciplinas voltadas para as normas de saúde e segurança do trabalho no currículo dos cursos investigados", a Figura 3 representa as menções dos 31 participantes.

Figura 3 - Existência de disciplinas relacionadas à saúde e segurança do trabalho no currículo dos cursos investigados.

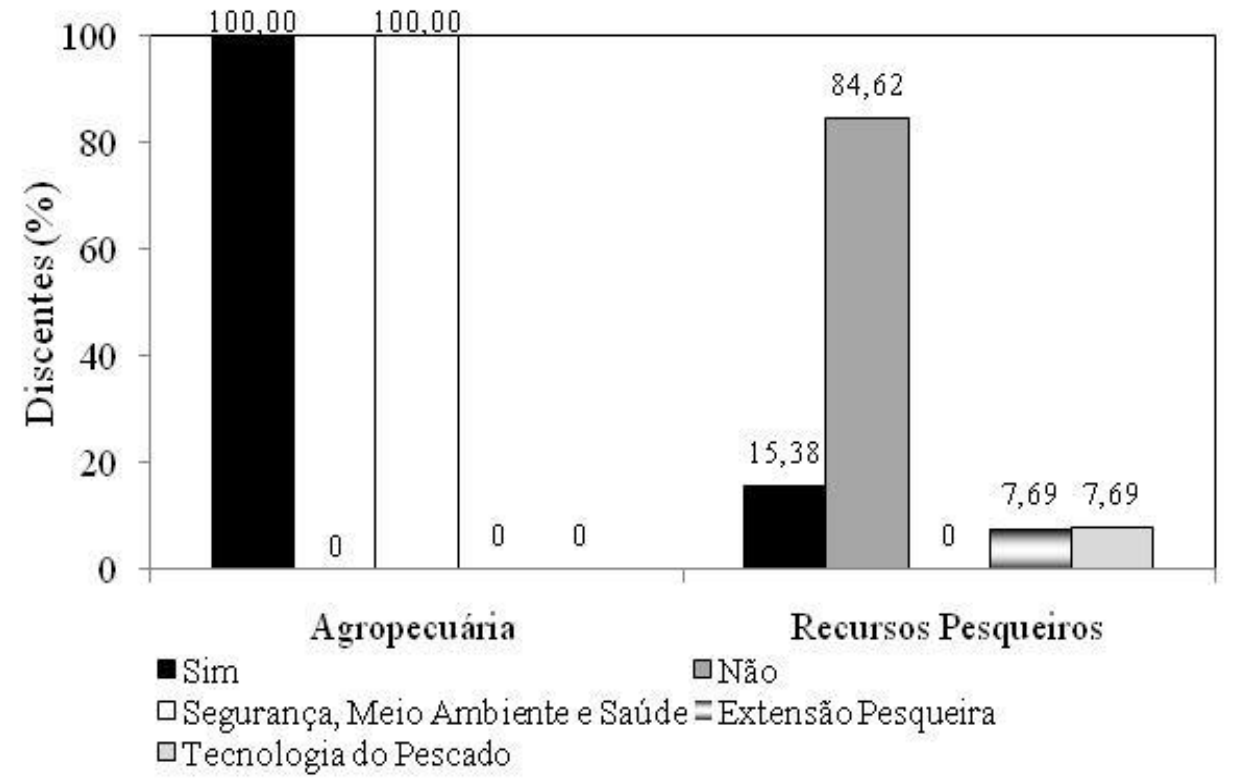

Fonte: Própria autoria.

Dentre os 18 discentes do terceiro ano do Ensino Médio Integrado em Agropecuária, 100,00\% mencionaram a existência da disciplina Segurança, Meio Ambiente e Saúde (SMS), ofertada no primeiro ano, o que pode ser elucidado nas falas: 
DIS10: Sim, é uma das disciplinas que faz parte da grade do curso, é SMS, é Segurança, Meio Ambiente e Saúde.

DIS14: Sim nós temos... a gente teve a matéria, mas que ela relatava sobre Segurança, Meio Ambiente e Saúde - SMS no campo.

DIS18: Só no primeiro ano que é Segurança, Meio Ambiente, só.

DIS20: Só SMS no primeiro ano.

Dentre os 13 discentes do terceiro módulo do Curso Subsequente de Recursos Pesqueiros, dois (15,38\%), reportaram outras disciplinas do curso nas quais o tema foi abordado; porém, 11 entrevistados $(84,62 \%)$, responderam não ter tido disciplina voltada à segurança. Algumas falas retratam a percepção daqueles que informaram a existência:

DIS1: Sim, a gente tem, na Tecnologia do Pescado [...] ele fala desses utensílios de EPI, né? Que é preciso a gente ter e na manipulação de alimentos, como luvas, como toucas, mas a gente não tem acesso porque o Campus não disponibiliza.

DIS5: Sim, Extensão Pesqueira, ela fala porque assim como a gente tem que tomar cuidado no momento da atividade.

Observando o indicador "minimização dos acidentes ocorridos com o uso de EPI", 31 (100,00\%) discentes, em ambos os cursos, relataram que os acidentes ou possíveis acidentes poderiam ser evitados ou minimizados mediante a utilização de EPI adequados às atividades. Algumas passagens foram relembradas pelos discentes, que indicavam a possibilidade de ocorrência de acidentes graves, entre eles, picadas de cobras e com instrumentos perfurocortantes, mas que poderiam ser evitados com os devidos procedimentos de proteção.

DIS8: [...] outra vez com uma cobra também eu tava capinando no estágio, aí eu tava aqui e o homem tava roçando, eu tava perto puxando o capim, aí tinha uma cobra, só que eu não vi, aí ele cortou ela em três pedaços, e se eu fosse mais pra lá ela podia me picar.

DIS11: [...] a gente tava estagiando, a gente tava fazendo limpeza da área, aí numa das fileiras a gente acabou pisando na cabeça de uma cobra e ela se enrolou todinha no equipamento, e quando a gente tirou ela do equipamento voltou a funcionar de novo e acertou o dedo e sangrou muito 
Finalizando as entrevistas com os 31 discentes, agora comentando sobre a “compreensão da responsabilidade de fornecimento do EPI", isto é, a quem consistia esse comprometimento, a Figura 4 exibe os questionamentos.

Figura 4. Percepção dos discentes quanto à responsabilidade de fornecimento e aquisição de EPI.

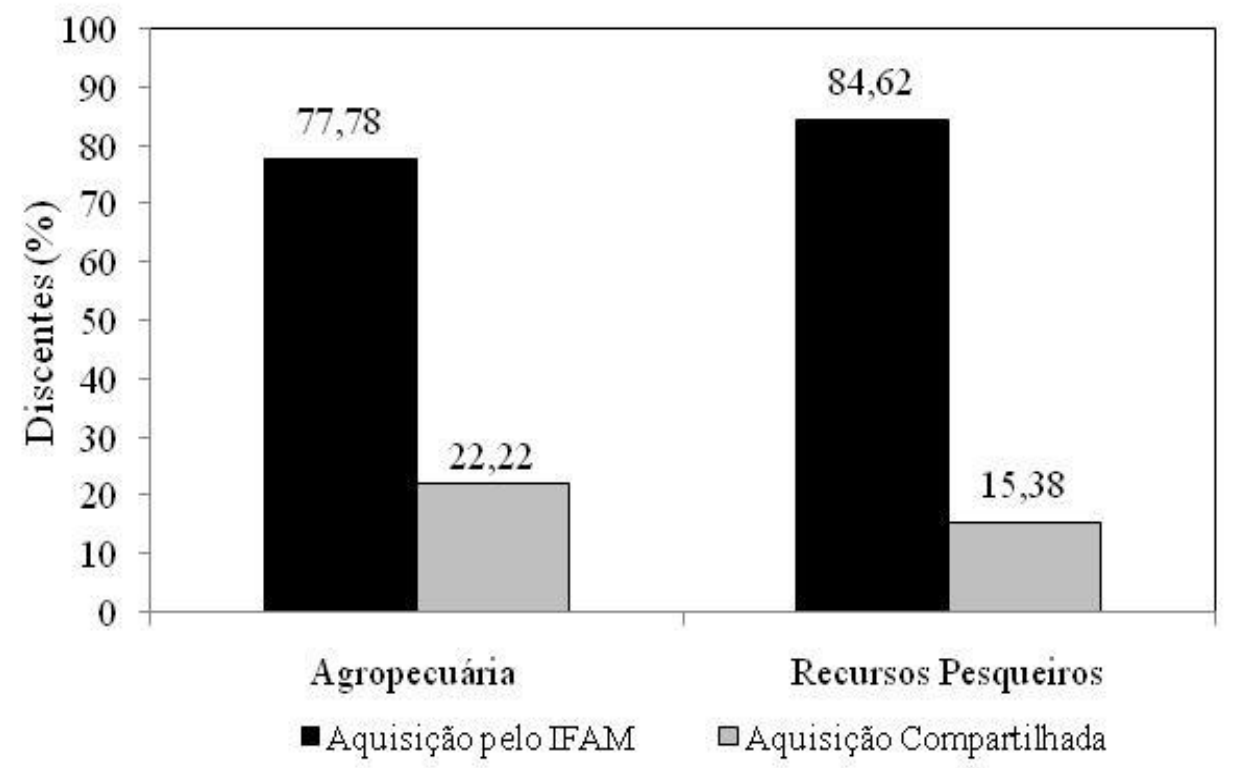

Fonte: Própria autoria.

Para $14(77,78 \%)$ discentes do terceiro ano do Ensino Médio Integrado em Agropecuária e 11 (84,62\%) do terceiro módulo do Curso Subsequente de Recursos Pesqueiros, existe o entendimento que seria o IFAM quem deveria fornecer os EPI, conforme falas a seguir:

DIS13: Bom, assim, pelo que foi passado pra gente, a única coisa que vem ser de nossa responsabilidade é a bota, os outros EPI como camisa de manga, boné, essas coisas, deveria ser responsabilidade do IFAM.

DIS24: Querendo ou não, a maioria dos alunos é de baixa renda.

DIS25: O IFAM que deveria fornecer pros alunos que nem todos têm possibilidades de comprar. 
De outro lado, quatro $(22,22 \%)$ discentes do terceiro ano do Ensino Médio Integrado em Agropecuária e dois $(15,38 \%)$ do terceiro módulo do Curso Subsequente de Recursos Pesqueiros, entenderam que a aquisição poderia ser compartilhada entre o IFAM e os discentes, conforme a fala a seguir:

DIS1: $\mathrm{Eu}$ acredito que as coisas que custam mais um pouquinho mais caro, eles deveriam, instituição deveria ajudar a gente a comprar e as coisas que têm o valor menor a gente poderia sim, tirar do nosso bolso.

Iniciando aqui a exposição dos resultados alcançados nas entrevistas com os servidores, sejam docentes ou técnicos, mais precisamente aquelas aplicadas sobre o indicador "histórico de acidente sofrido durante as atividades práticas", a Tabela 1 apresenta as respostas disponibilizadas pelos 14 servidores.

Tabela 1 - Relatos dos servidores quanto a acidentes sofridos e presenciados.

\begin{tabular}{|c|c|c|c|c|c|c|c|c|c|}
\hline \multirow{2}{*}{ Servidores } & \multirow{2}{*}{$\begin{array}{l}\text { Participantes } \\
\text { da pesquisa }\end{array}$} & \multicolumn{4}{|c|}{ Acidente sofrido } & \multicolumn{4}{|c|}{ Acidente presenciado } \\
\hline & & Sim & $\%$ & Não & $\%$ & Sim & $\%$ & Não & $\%$ \\
\hline Docentes & 11 & 4 & 36,36 & 7 & 63,64 & 7 & 63,64 & 4 & 36,36 \\
\hline Técnicos & 3 & 1 & 33,33 & 2 & 66,67 & 3 & 100,00 & 0 & 0,00 \\
\hline Total & 14 & 5 & 35,71 & 9 & 64,29 & 10 & 71,43 & 4 & 28,57 \\
\hline
\end{tabular}

Fonte: Elaborada pelos autores com base nos dados obtidos nas entrevistas.

Dentre os 11 docentes entrevistados, quatro (36,36\%) afirmaram já ter sofrido e ou presenciado acidentes. Algumas falas podem descrever o mencionado por aqueles que relataram algum tipo de acidente:

DOC7: Sim, pequenas escoriações, né? De estar dentro dos viveiros, [...], pequenos cortes também, quando você manuseia peixes que são agressivos [...] perfurações de agulha também, quando a gente vai trabalhar parte de reprodução, que eu já perfurei também. 
DOC8: [...] só uma vez que uma piranha mordeu no meu dedo... (risos), mas não foi acidente não, foi descuido. [...] não informei não, o instituto não, até porque foi uma mordida pequeninha, não foi caso sério, não.

No segmento dos técnicos, apenas um (33,33\%) afirmou ter se acidentado em campo, por abelhas africanas, conforme relatado a seguir:

TEC1: Eu já passei por uma situação que foi com as abelhas [...] mas é um caso que não era possível prever e nem acredito que houvesse algum EPI que pudesse evitar, porque a gente não tinha como fazer o manejo da despesca usando por exemplo um equipamento de proteção, porque os alunos todos passaram, né? pela ferrada das abelhas e tivemos que ir para o hospital, inclusive [...].

Também há relatos que chamam a atenção quanto à ocorrência de acidentes dentro da instituição, especificamente no laboratório, como fica claro na fala do técnico abaixo:

TEC1: [...] eu precisava formolizar uns peixes pra atualizar a coleção e a nossa capela de exaustão tava danificada, e [...] durante a manipulação da pipeta, espirrou a solução de formol nos meus olhos [...] e eu fiquei muito tempo com o olho inflamado assim, vermelhado; nesse dia não consegui mais trabalhar [...].

Com relação às respostas prestadas durante a entrevista sobre o indicador "testemunho de acidentes com colegas em atividades práticas", sete $(63,64 \%)$ docentes e três $(100,00 \%)$ técnicos responderam que sim (Tabela 1). Algumas falas deixam claras tais respostas:

DOC4: Alguns alunos já se acidentaram. A maioria dos acidentes nas minhas disciplinas é com facas nas mãos e dedos. Ferimentos devido aos esporões dos peixes que ferem as pernas. Lembro que em 2013 nós tivemos um aluno que teve acidente com peixe elétrico que estava fazendo atividade de limpeza do viveiro e ao cortar o capim bateu o terçado e levou choque.

DOC6: Já, eu já verifiquei corte, às vezes tá manuseando algum instrumento de corte, até mesmo [...] essa parte de corte no laboratório principalmente na parte de tecnologia de alimentos, às vezes, se corta com faca né, tem alguns outros equipamentos que causam lesão, [...] eu lido com estilete, com gilete, às vezes não tendo o cuidado né, às vezes talvez até o uso de uma luva um pouquinha mais grossa pudesse evitar, mas acabam tendo esses cortes. 
DOC7: Já nas minhas aulas, já teve algumas situações que, de corte também de pé, muitas das vezes a gente dá a diretriz para o aluno entrar de bota e a gente tá fazendo as atividades e ele tá com o equipamento e retira na água, a gente não percebe; ai, só percebe quando acontece o acidente.

Analisando o indicador "conhecimento de normas e procedimentos internos de segurança", as entrevistas com os servidores revelaram que 14 (100,00\%) dos entrevistados desconheciam a existência de normas internas do Campus ou de abrangência às demais unidades do IFAM, relacionadas às questões de segurança, conforme relatos a seguir:

DOC2: Não, não tenho nenhum tipo de conhecimento dessas normas internas que tenha na nossa instituição, não.

DOC4: Não, na verdade não foi passada nenhuma informação; a partir do momento que eu comecei no Instituto Federal. A gente sabe, pela questão de produção, né? Que é necessária, mas pela questão da instituição de informar, não.

TEC2: Interna do Campus não temos conhecimento de nenhuma norma, nenhuma resolução [...] instituída no Campus. [...] Também a nível sistêmico, nós não temos conhecimento se tem alguma norma referente à segurança do trabalho.

TEC3: Não, interna normatização eu desconheço. Nós nos amparamos nas legislações mais abrangentes, né? Porque a gente, como servidor, tem compromisso de zelar pela integridade do aluno e a nossa né?

Observando o indicador "riscos e perigos nos locais das atividades práticas", 14 (100,00\%) dos servidores mencionaram a existência dos mesmos. A esse respeito, chamou atenção os relatos já apresentados sobre as situações vivenciadas no Laboratório de Ecologia Pesqueira.

TEC1: A gente não pode esperar uma condição ideal de estrutura pra que essa segurança seja feita. Por exemplo, [...] eu precisava formolizar pra atualizar a coleção de peixes [...]e a nossa capela de exaustão tava danificada [...].

TEC2: Mas a ausência da capela da exaustão foge da minha competência, né? [...] já haviam informado, mas a gente não podia deixar de fazer o trabalho porque os peixes da coleção eram utilizados nas aulas de anatomia, precisava ter esse material, né? E eu tava na época responsável pelo laboratório. 
Terminando, referente ao indicador "promoção da saúde e prevenção de doenças e acidentes", notou-se claramente, de acordo com 14 (100,00\%) dos servidores, a necessidade de realização de atividades voltadas para a sensibilização dos discentes quanto à sua saúde e segurança nas atividades. Uma dessas atividades seria quanto ao uso dos equipamentos, conforme se menciona a seguir:

DOC8: [...] às vezes, os alunos não têm recursos pra adquirir questões de protetor solar, o protetor solar de qualidade aí tem um certo preço, aí a gente faz essa questão de orientação né [...].

DOC9: [...] a gente enquanto docente [...] encontra uma dificuldade pra gente formar um profissional que seja correto no uso de equipamentos, é muito complicado porque é uma questão de cultura, [...] eles vão estar aí indo pro mercado do trabalho e tem que ter essa consciência da importância do uso dos equipamentos de proteção, pra evitar aí dano, sequelas ou até mesmo a morte no futuro.

Os docentes entendem que existe uma necessidade de mais atividades preventivas relacionadas ao uso de EPI, visto que hoje o Campus não os fornece para servidores e tampouco para discentes.

\section{DISCUSSÃo}

Entre os entrevistados houve um percentual significativo de relatos de acidentes durante as atividades práticas. Dos 18 discentes entrevistados do terceiro ano do Ensino Médio Integrado em Agropecuária, 16,67\% relataram ter sofrido acidente; entretanto, a maioria $(83,33 \%)$ negou ter se acidentado. É possível inferir que o índice relativamente baixo de acidentes possa estar relacionado ao conhecimento obtido na disciplina Segurança, Meio Ambiente e Saúde (SMS) mencionada por todos os entrevistados da turma de Agropecuária, que é ministrada no primeiro ano do curso, a qual proporciona a ampliação de conhecimentos e acesso às normas de segurança para a prevenção de doenças e acidentes, preparando os discentes para a proteção de acidentes e doenças, ainda que não possuam EPI.

A mesma pergunta foi feita aos 13 entrevistados do terceiro módulo do Curso Subsequente de Recursos Pesqueiros. Nestes estudantes, a porcentagem de acidentes 
aumentou para 38,46\%, quando comparada com a turma de Agropecuária, ou seja, uma proporção 2,3 vezes maior do que aquela relatada no grupo estudantil anterior. Provavelmente, a não oferta no curso de Recursos Pesqueiros da disciplina SMS possa ter influenciado em tal resultado.

Frazão et al. (2019) salientaram, como uma das causas mais frequentes de acidentes nas atividades relacionadas à pesca, a mordedura de piranha (Pygocentrus natterere), que representa 11,11\% dos acidentes. Haddad Junior (2003) corroborou que os acidentes causados por piranhas são traumáticos, devido a suas características anatômicas, dando destaque aos dentes que, ao morder, provocam lacerações e sangramentos importantes. Destacou alguns peixes que provocam acidentes, como o peixe-elétrico (Electrophorus electricus) que, quando tocado, pode aplicar correntes elétricas de até 300 volts, e o candiru (Vandellia cirrhosa), um pequeno bagre hematófago e parasita natural de guelras de grandes peixes, que pode raramente penetrar na uretra e no ânus de seres humanos, sendo de difícil extração.

Servidores e discentes relataram contatos e acidentes como algo corriqueiro, natural ou mesmo que não pudesse gerar situações mais graves como, por exemplo, amputação de um dedo ocasionada pela mordida de um peixe extremamente agressivo como a piranha.

É preciso salientar, com relação a doenças e acidentes em atividades laboratoriais ou de campo, que a ausência de comunicação e sua respectiva notificação pode dificultar o processo de planejamento da equipe multidisciplinar. Por outro lado, essa omissão de servidores e discentes subestima o risco potencial de acidentes, que continuarão a existir, devido à diversidade de espécies da fauna amazônica que, dependendo da espécie animal envolvida, pode causar acidentes com consequências graves ou mesmo fatais.

Os entrevistados também relataram exposição a acidentes com abelhas e vespas. Martins e Becil Junior (2018) salientaram que a exposição acidental pode ser letal, se os indivíduos forem altamente alérgicos, podendo esses desenvolver processo anafilático sistêmico, o que, no caso de discentes ou servidores em atividade de campo, poderia levar ao óbito, por serem, essas atividades, eventualmente distantes de centros médicos.

Nesse sentido, os servidores e discentes que participam de atividades de campo estão corriqueiramente expostos a esse tipo de acidente, o que torna tanto a proteção individual 
como a orientação de como proceder para evitar ataques de suma importância, para prevenir acidentes que poderão ser potencialmente graves.

Assim, o risco pode ser entendido pela exposição de servidores e discentes a locais e situações considerados potencialmente perigosos. Barsano e Barbosa (2018) enfatizaram a necessidade de prever situações perigosas e eliminá-la em sua origem. Para que isto ocorra, seria necessária uma perícia, que deveria ser realizada por profissional competente na área (Médico do Trabalho ou Engenheiro do Trabalho), sendo uma das funções da perícia, a identificação das situações de riscos envolvidos nas atividades e apontá-los num Laudo Pericial.

Dentre os riscos ocupacionais, a Norma Regulamentadora n.. 9 (BRASIL, 1978), definiu os agentes físicos, químicos e biológicos como riscos ambientais, que, em função de sua natureza, concentração ou intensidade e tempo de exposição, são capazes de causar danos à saúde do trabalhador e, a depender de alguns fatores, podem gerar o adicional de insalubridade (SANTOS, 2016).

Tais riscos, sendo laborais para os docentes, também existem, na mesma medida, para os discentes expostos, devendo ser considerados pelas instituições que oferecem cursos cujas atividades práticas expõem seus discentes aos mesmos riscos. Essa identificação de possíveis riscos somente é possível mediante a inspeção prévia.

A avaliação do risco leva em conta, tanto sua probabilidade de causar danos às pessoas, a frequência da exposição e o nível de gravidade do dano que possa ocorrer. Por conseguinte, os riscos encontrados devem ser mapeados e categorizados, sendo os riscos ergonômicos e organizativos agrupados em uma mesma categoria, em decorrência da sua semelhança e/ou repetição (XIMENES NETO; CRISPIM, 2019).

Normalmente, as atividades práticas dos cursos investigados são realizadas em áreas rurais e raramente no próprio Campus, devido à ausência de instalações. Independentemente de ser dentro ou fora das instalações do IFAM, ambas têm em comum o fato de serem realizadas em ambiente amazônico, o que nem sempre é levado em consideração quando a atividade é planejada.

Muller e Leite (2014) e Barsano e Barbosa (2018) orientaram sobre o conceito prevencionista, no qual são abordados não somente os acidentes do trabalho como uma causa 
de dano real ao trabalhador, mas, principalmente, chamam a atenção sobre a antecipação de certos eventos através do olhar prevencionista dos profissionais envolvidos, com a finalidade de mitigar os incidentes, desde uma pequena lesão, uma grave lesão ou até mesmo um acidente fatal (morte do trabalhador).

Os servidores relataram que algumas situações ocorrem devido aos discentes não atenderem às determinações na hora das atividades. Apesar do posicionamento perfeitamente compreensível dos docentes, é importante ressaltar que somente a presença dos assistentes ou técnicos, sem o uso de EPI adequados pelos envolvidos nas atividades, não seria suficiente para evitar a ocorrência dos acidentes.

Para tanto, observar o meio ambiente do trabalho e ensino é uma das formas de minimizar a ocorrência de acidentes. A esse respeito, “o meio ambiente do trabalho é [...] todo espaço, físico ou abstrato, que, ao interagir com o trabalhador o influencia de maneira positiva ou negativa, alterando seu estado físico, psíquico e social (BARSANO; BARBOSA, 2018, p. 65).

Extrapolou-se o pensamento do autor para o ambiente de educação, principalmente em se tratando de cursos técnicos, pois nos mesmos frequentemente poderia haver a exposição dos discentes aos mesmos riscos a que se encontram expostos os trabalhadores da área. Nesse sentido, deve-se, igualmente, ter atenção às atividades práticas e laboratoriais dos cursos, de modo a identificar esses riscos e proceder as medidas de prevenção de acidentes e proteção dos estudantes, de maneira que se torne possível conciliar o aprendizado prático com a segurança necessária.

As situações descritas anteriormente corroboram para a ocorrência de acidentes, uma vez que, para desempenhar suas atividades laborais, servidores e discentes adaptam materiais e equipamentos em condições nem sempre adequadas de funcionamento, assumindo, desse modo, riscos desnecessários com relação à exposição a acidentes e doenças e à exposição a substâncias tóxicas.

No Campus Parintins, a elaboração de manuais contendo normas de segurança na utilização de laboratórios se faz necessária, no sentido de normatizar a utilização desses espaços e para a padronização de processos e procedimentos. A questão principal é que não há até o momento, no âmbito do Campus, procedimentos de segurança estabelecidos. 
Nesse sentido, poderia, por exemplo, através do estímulo aos docentes dos cursos investigados, e com incentivo dos mesmos aos discentes na realização de Projetos de Conclusão de Curso Técnico (PCCT), buscar temas de Saúde e Segurança para os diversos espaços de ensino, pesquisa e extensão.

Outro ponto sensível é quanto à capacidade econômica dos discentes para a aquisição de equipamentos, haja vista as dificuldades financeiras de suas famílias em adquiri-los. Essa informação é corroborada com os dados obtidos através do anuário estatístico realizado no Campus no ano de 2019. Os dados revelaram baixa renda familiar, confirmando relatos de discentes, quanto às dificuldades financeiras e a impossibilidade de adquirir os EPI.

Nessa perspectiva, a legislação educacional não é explícita, ou seja, não obriga a instituição de ensino a fornecer os EPI, mas, por outro lado, também não proíbe seu fornecimento. Seguindo esse raciocínio e considerando a escassez de publicações a esse respeito, foi solicitado ao Ministério da Educação (MEC), esclarecimentos quanto à obrigatoriedade do IFAM em fornecer EPI para os discentes. Em resposta, o MEC salientou que a instituição, dentro de sua autonomia administrativa e orçamentária, pode, se quiser, disponibilizar EPI aos discentes.

$\mathrm{O}$ artigo terceiro da Política Nacional de Assistência Estudantil ampliou as condições de permanência de estudantes e contemplou linhas de assistência: moradia estudantil, auxílio transporte, auxílio alimentação, auxílio creche, auxílio material didático, auxílio moradia e atenção à saúde (BRASIL, 2010). Desse modo, não havendo restrição legal e considerando que o IFAM, Campus Parintins, goza de autonomia administrativa, financeira e patrimonial, poderia, dentro de um processo de planejamento financeiro, adquirir e fornecer kits desses equipamentos.

Os relatos indicaram que os servidores jamais receberam EPI, o que os leva à exposição a riscos e acidentes. Mesmo na ausência de normas internas de segurança, os servidores utilizam os conhecimentos advindos da experiência profissional, além da aplicação das legislações vigentes, no que se refere à Saúde e Segurança do Trabalho (SST). Dentre elas, destaca-se Portaria MTB n. 977 , de 24 de outubro de 2018, que define EPI como todo dispositivo ou produto, de uso individual utilizado pelo trabalhador, destinado à proteção de riscos suscetíveis de ameaçar a segurança e a saúde no trabalho (BRASIL, 2018) 
Considerando os relatos dos servidores, foi solicitado ao IFAM, por meio do Serviço de Informação ao Cidadão (e-SIC), esclarecimentos quanto à existência de normas relativas à segurança do trabalho. O IFAM, através do Núcleo de Segurança do Trabalho (NST) respondeu: “[...] estamos trabalhando em um manual institucional com o objetivo de nortear todas as atividades e procedimentos de segurança que deverão ser adotados para diminuir ou excluir os acidentes de trabalho". Importante ressaltar que tal manual, quando disponibilizado, deverá atingir tão somente os servidores da instituição, não contemplando a segurança dos discentes. A resposta emitida pelo NST corrobora os relatos dos servidores quanto ao desconhecimento de normas.

A Fundação Jorge Duprat Figueiredo, de Segurança e Medicina do Trabalho (FUNDACENTRO), através do e-SIC comentou: "Desconhecemos uma norma regulamentadora nos moldes da NR n. ${ }^{\circ}$ 6, para órgãos públicos federais”. Recorreu à analogia de normas e indicou a observância da Orientação Normativa nº 4, de 14 de fevereiro de 2017, que objetivou uniformizar entendimentos no tocante à concessão dos adicionais de insalubridade e periculosidade (BRASIL, 2017).

Esses adicionais somente podem ser concedidos mediante Laudo Técnico Pericial, daí a importância da elaboração de laudo, considerando não apenas os ambientes internos ao Campus, mas, fundamentalmente, a zona rural, espaço prioritário das atividades práticas desses cursos. Vassem et al. (2017) enfatizaram a segurança do trabalho e as preocupações sobre as perdas financeiras e não financeiras relacionadas a fatalidades, lesões e doenças que impactam nas organizações, famílias, sociedades e principalmente nas próprias vítimas.

É possível perceber o quanto é necessário ofertar atividades educativas, no sentido de massificar as informações sobre saúde e segurança nas atividades práticas, possibilitando que servidores e discentes discutam, a partir das situações já vivenciadas ou testemunhadas, alternativas para evitar doenças e acidentes. Para isso ocorrer, deve haver completa mudança de mentalidade entre gestão, servidores e discentes.

\section{CONSIDERAÇÕES FINAIS}


Os objetivos da pesquisa foram satisfatoriamente alcançados, sendo possível identificar tanto as atividades já existentes no Campus acerca da promoção da saúde e prevenção de acidentes, quanto as percepções de servidores e discentes sobre os EPI, seu uso e a quem caberia a responsabilidade de ofertá-los. Além disso, investigou-se a percepção de discentes e servidores, quanto aos métodos e processos de segurança.

Não há dúvidas entre o público investigado quanto aos benefícios da utilização de itens de segurança e quanto à necessidade do IFAM, Campus Parintins, desenvolver uma política de prevenção, que possa minimizar as situações de risco existentes.

À medida que a pesquisa avançava, percebeu-se uma postura diferente dos servidores, após o contato com o pesquisador e o acesso às informações de saúde e segurança; quando passaram a considerar as situações de riscos existentes e planejar suas práticas de modo mais seguro. Outro movimento percebido foi quanto à preocupação da gestão em melhorar os ambientes, dotando-os de infraestrutura adequada às atividades e fornecimento de EPI a servidores, além da colocação de placas de advertência sobre uso de EPI nos laboratórios.

Nesse sentido, o fator planejamento é outro ponto que merece destaque, devido à determinação de levantamentos e elaboração de termos de referência para aquisição de kits de EPI, que certamente irão colaborar para que as práticas sejam realizadas de forma segura, evitando acidentes. Também já há manifestação do gestor quanto ao apoio na elaboração e publicação de manuais de procedimentos padronizados, conforme cada tipo de atividade a ser realizada, que começa a ganhar forma com a união de esforços de servidores, principalmente aqueles que atuam nos locais de prática em que outros estudos sobre o tema poderão ser realizados, abordando, por exemplo, planejamento, acompanhamento e execução de atividades acadêmicas dentro ou fora da instituição.

Por fim, os caminhos demonstrados para a promoção da saúde e prevenção de doenças, incluem entre outras ações a adoção de padrões internos de segurança, os quais se fazem urgentes nas atividades realizadas, seja em espaços abertos ou em laboratórios de ensino. A segurança de servidores e discentes não pode ser negligenciada, nem tratada à margem de sua real importância. 


\section{REFERÊNCIAS}

BARDIN, L. Análise de conteúdo. São Paulo: Almedina Brasil, 2011.

BARSANO, P. R.; BARBOSA, R. P. Higiene e segurança do trabalho. 2. ed. São Paulo: Érica, 2018.

BRASIL. Decreto n. 3.724 , de 15 de janeiro de 1919. Regula as obrigações resultantes dos acidentes no trabalho. Diário Oficial [da] República Federativa do Brasil, Poder Executivo, Brasília, DF, 18 jan. 1919. Seção 1, p. 1013.

BRASIL. Norma Regulamentadora n. ${ }^{\circ}$, de 8 de junho de 1978. Estabelece a obrigatoriedade da elaboração e implementação, por parte de todos os empregadores e instituições que admitam trabalhadores como empregados, do Programa de Prevenção de Riscos Ambientais - PPRA, visando à preservação da saúde e da integridade dos trabalhadores. Diário Oficial [da] República Federativa do Brasil. Poder Executivo, Brasília, DF, 6 jul. 1978.

BRASIL. Decreto n. ${ }^{\circ}$ 7.234, de 19 de julho de 2010. Dispõe sobre o Programa Nacional de Assistência Estudantil PNAES. Diário Oficial [da] República Federativa do Brasil. Poder Executivo, Brasília, DF, 20 Jul. 2010. Seção 1, p. 5.

BRASIL. Resolução n. ${ }^{\circ}$ 466, de 12 de dezembro de 2012. Dispõe sobre as diretrizes e normas regulamentadoras de pesquisas envolvendo seres humanos. Diário Oficial [da] República Federativa do Brasil, Poder Executivo, Brasília, DF, 13 jun. 2013. Seção 1, p. 59.

BRASIL. Orientação Normativa $n .^{\circ}$ 4, de 14 de fevereiro de 2017. Estabelece orientação sobre a concessão dos adicionais de insalubridade, periculosidade, irradiação ionizante e gratificação por trabalhos com raios-x ou substâncias radioativas, e dá outras providências. Diário Oficial [da] República Federativa do Brasil. Poder Executivo, Brasília, DF, 23 fev. 2017. Seção 1, p. 68.

BRASIL. Portaria MTB n. .877 , de 24 de outubro de 2018. Altera a Norma Regulamentadora n.. 06 - Equipamento de Proteção Individual - EPI. Diário Oficial [da] República Federativa do Brasil. Poder Executivo, Brasília, DF, 26 out. 2018. Seção 1, p. 82.

FRAZÃO, F. B.; FERREIRA, L. K. S.; FRAZÃO, R. H. N.; LOUZEIRO, N. M. Riscos ocupacionais e medidas de proteção dos trabalhadores identificados em uma piscicultura no município de Santa Rita-MA. Revista Brasileira de Engenharia de Pesca, Santa Rita, v. 12, n. 1, p. 50-61, jun. 2019. Disponível em: <http://ppg.revistas.uema.br/index.php/REPESCA/article/view/1682>. Acesso em: 20 jun. 2020.

GERHARDT, T. E.; SILVEIRA, D. T. Métodos de pesquisa. Porto Alegre: Editora UFRGS, 2009.

GOOGLE EARTH. Instituto Federal de Educação, Ciências e Tecnologia do Amazonas, IFAM. Campus Parintins. 2019. Disponível em: <https://www.google.com.br/intl/pt-BR/earth/>. Acesso em: 12 nov. 2019.

HADDAD JUNIOR, V. Animais aquáticos de importância médica no Brasil. Revista da Sociedade Brasileira de Medicina Tropical, Uberaba, v. 36, n. 5, p. 591-597, set./out. 2003. Disponível em: $<$ https://www.scielo.br/pdf/rsbmt/v36n5/a09v36n5.pdf>. Acesso em: 18 jul. 2020.

MARTINS, A.; BECIL JUNIOR, M. R. Acidentes com animais peçonhentos da ordem Hymenoptera (abelhas e vespas): principais complicações em países da América Latina e Caribe. Brazilian Journal of Health Review, Curitiba, v. 1, n. 1, p. 220-232, jul./set. 2018. Disponível em: $<$ https://www.brazilianjournals.com/index.php/BJHR/issue/view/26https://www.brazilianjournals.com /index.php/BJHR/article/view/669>. Acesso em: 25 abr. 2020.

MINAYO, M. C. S. Ciência, técnica e arte: o desafio da pesquisa social. In: MINAYO, M. C. S.; DESLANDES, S. F.; CRUZ NETO, O.; GOMES, R. (Orgs.). Pesquisa social: teoria, método e criatividade. Petrópolis: Vozes, 2010. p. 929.

MULLER, C.; LEITE, P. Práticas em saúde e segurança do trabalho. Curitiba: Instituto Federal do Paraná, 2014. 
PARINTINS. Certidão de viabilidade ambiental n. ${ }^{\circ}$ 036/2009. Parintins: Secretaria Municipal de Desenvolvimento Sustentável e Meio Ambiente, 2009.

SANTOS, Y. M. A. Segurança, Meio Ambiente e Saúde. Recife: Instituto Federal de Educação, Ciência e Tecnologia de Pernambuco, 2016.

VASSEM, A. S.; FORTUNATO, G.; BASTOS, S. A. P.; BALASSIANO, M. Fatores constituintes da cultura de segurança: olhar sobre a indústria de mineração. Gestão e Produção, São Carlos, v. 24, n. 4, p. 719-730, out. 2017. Disponível em: <https://www.scielo.br/pdf/gp/v24n4/0104-530X-gp-0104-530X1960-16.pdf>. Acesso em: 22 jul. 2020.

XIMENES NETO, F. R. G., CRISPIM, F. S. P. Riscos à saúde de trabalhadores rurais no extrativismo da palha de carnaúba. Enfermagem em Foco, Sobral, v. 10, n. 2, p. 17-23, abr. 2019. Disponível em: <http://revista.cofen.gov.br/index.php/enfermagem/article/view/2281/513>. Acesso em: 12 mai. 2020.

\section{(cc) BY}

Este trabalho está licenciado com uma Licença Creative Commons - Atribuição 4.0 Internacional. 